\title{
P. Berthier, Le Théâtre en France de 1791 à 1828, Le Sourd et la Muette
}

\section{Lise Sabourin}

\section{(2) OpenEdition}

10 Journals

\section{Édition électronique}

URL : http://journals.openedition.org/studifrancesi/9971

DOI : 10.4000/studifrancesi.9971

ISSN : 2421-5856

Éditeur

Rosenberg \& Sellier

\section{Édition imprimée}

Date de publication : 1 août 2017

Pagination : 362-363

ISSN : 0039-2944

\section{Référence électronique}

Lise Sabourin, «P. Berthier, Le Théâtre en France de 1791 à 1828, Le Sourd et la Muette », Studi Francesi [En ligne], 182 (LXI | II) | 2017, mis en ligne le 01 août 2017, consulté le 06 janvier 2021. URL : http:// journals.openedition.org/studifrancesi/9971 ; DOI : https://doi.org/10.4000/studifrancesi.9971

Ce document a été généré automatiquement le 6 janvier 2021.

\section{(c) $(1) \&$}

Studi Francesi è distribuita con Licenza Creative Commons Attribuzione - Non commerciale - Non opere derivate 4.0 Internazionale. 


\title{
P. Berthier, Le Théâtre en France de 1791 à 1828, Le Sourd et la Muette
}

\author{
Lise Sabourin
}

\section{RÉFÉRENCE}

PATRICK BERTHIER, Le Théâtre en France de 1791 à 1828, Le Sourd et la Muette, Paris, Honoré

Champion, 2014, $982 \mathrm{pp}$.

1 Partant de la libératrice loi Le Chapelier de 1791 et terminant en 1828 à l'aurore du succès romantique que fut Henri III et sa cour, Patrick Berthier, pour ce volume de la série «Histoire du théâtre français», veut construire une «histoire concrète du spectacle vivant» tel que l'appréciaient vraiment les spectateurs du temps. C'est pourquoi, après avoir accompli l'immense tâche de recenser toutes les œuvres représentées durant cette période (voir le calendrier théâtral, pp. 643-820), il retient les pièces qui l'ont été plus de cent fois pour critère de succès, et non pas seulement la réception critique qui a pu accompagner, mettre en valeur ou dénigrer des ouvrages en fait moins vus par le public.

2 C'est ce qui explique le choix du sous-titre, qui va du Sourd ou l'Auberge pleine de Desforges, comédie jouée plus de cinq cents fois durant la dernière décennie du XVIII ${ }^{\mathrm{e}}$ siècle, à La Muette de Portici d'Auber et Scribe, opéra représenté presque autant de 1828 à 1900 (avant sa reprise, non pas seulement comme le dit l'auteur en 2012 à l'OpéraComique, mais, bien meilleure, à Ravenne en 1991). Patrick Berthier recense également tous les genres, notant combien les catégorisations de pièces sont fluctuantes dans l'esprit de leurs auteurs comme d'ailleurs du public, qui cherche finalement surtout le divertissement et l'émotion, qu'il aille voir une tragédie, une comédie, un mélodrame ou un vaudeville, une féerie ou un mime.

3 Patrick Berthier, après son introduction méthodologique (pp. 7-20), organise alors en trois temps cet énorme corpus, dont il ne s'autorise à analyser que les œuvres retenues 
comme majeures selon leur durée de visibilité, sans pour autant évidemment oublier ce que la postérité a parfois préféré y sélectionner ou y substituer.

4 La première partie, «Avatars de la liberté (1791-1800)» (pp. 21-216), se décompose en trois chapitres, «Avant la Terreur» (1791-1792), «Scènes sous contrôle» (1793-1794), «Liberté et contrainte» (1795-1800) au fil des régimes politiques et de leurs répercussions sur la prolifération ou la restriction des théâtres. À la dénomination évolutive du Théâtre-Français (de la Nation, de la République, avec risque récurrent de scission) et à l'ouverture de salles promises à bel avenir (Ambigu, Gaîté) répondent l'interdiction de L'Ami des lois de Laya par la tâtillonne Terreur et la progression des sujets historiques ou religieux à portée militaire ou politique (Fénelon ou les reliques de Cambrai de M.-J. Chénier, Paméla ou la Vertu récompensée de Neufchâteau, Mutius Scaevola de Luce de Lancival). Après Thermidor, la quête de divertissement multiplie comédies et vaudevilles, même si le Directoire tente de remettre au pas une effervescence théâtrale que seul le consul de Brumaire réussira à endiguer.

5 La deuxième partie, «Napoléon Bonaparte et son fantôme (1800-1821)» (pp. 217-428), voit d'abord évoluer la situation «Vers les privilèges» (1800-1807), puis les théâtres «Vivre à huit» (1807-1814), avant que ne soit brandi «Le gourdin de Germanicus ou les limites du bonapartisme» (1814-1821). Le foisonnement révolutionnaire est contenu par l'affectation des genres aux salles et l'intervention des censeurs qui ne parviennent pas pour autant à empêcher le public de découvrir sous couleur historique (Les Templiers de Raynouard en 1805, La Mort d'Henri IV de Legouvé en 1806, Christophe Colomb de Lemercier en 1809) la rénovation en marche. La comédie et le vaudeville triomphent aux Variétés et au Vaudeville, avec les débuts de Scribe, le mélodrame est préféré à la tragédie que voudrait voir renouvelée l'Empereur: ainsi La Vestale de Spontini et Les Deux Gendres d'Étienne marquent-ils les préférences du public. Après l'abdication, le succès du Sylla de Jouy, des Vêpres siciliennes de Delavigne et de la Marie Stuart de Lebrun sera une autre forme de réponse populaire, tandis que se poursuit le train-train de l'opéra-comique, que sont accueillies avec faveur folies-vaudevilles et pantomimes, que stagne puis décline doucement la tragédie et même la comédie classique sous la Restauration.

6 La troisième partie, «Vers la nouveauté? (1819-1828)» (pp. 429-632), est rythmée par les titres célèbres: «Des Vêpres siciliennes à L'Auberge des Adrets» (1819-1823), «De Racine et Shakespeare à Clara Gazul» (1823-1825), "Avant et après Cromwell» (1826-1828). La création du prolixe Gymnase et du fugitif Panorama-Dramatique accompagne la codification opérée désormais $d u$ vaudeville et du mélodrame, et les directeurs s'organisent pour composer des soirées alléchantes par leur contenu (trois ou quatre brèves pièces diverses, deux plus longues - une ancienne, une récente, ou de genres différents) ou leurs vedettes (de Talma à Frédérick Lemaître, de Mlle Mars à Rose Chéri, sans oublier les représentations à bénéfice pour récompenser des acteurs plus mineurs mais appréciés). Puis, tandis que se prépare encore discrètement la dramaturgie romantique, par la théorisation stendhalienne ou le subterfuge mériméen, les théâtres continuent sur leur lancée en multipliant les pièces susceptibles de recettes (tels les effets de série sur un même sujet, de Trilby à Polichinelle, ou les spectacles à public socialement choisi, comme le juvénile théâtre Comte ou le physique Cirque-Olympique) ou en se conformant aux attentes politiques (célébration de l'indépendance grecque, de la saint Louis, du couronnement de Charles X). Mais la double venue si contrastée de la troupe anglaise en 1822 et 1827 marque l'évolution de la lecture shakespearienne, 
désormais accessible par la traduction moins édulcorée de Guizot face aux adaptations de Ducis, et la préface de Cromwell peut alors proclamer la nécessité d'un théâtre moderne comme le fut en son temps celui du grand Will, même sur sujets historiques anciens.

7 Patrick Berthier fournit avec ce livre une véritable somme, par la richesse de son recensement, par l'analyse de pièces souvent citées mais rarement lues (voir par exemple sa présentation de L'Auberge des Adrets, pp. 467-470, ou celle Trente Ans ou la Vie d'un joueur, pp. 586-588), que complètent le répertoire des principaux auteurs et acteurs, la bibliographie d'histoire du théâtre ( $\mathrm{XVIII}^{\mathrm{e}}-\mathrm{XIX}^{\mathrm{e}}$, puis $\mathrm{XX}^{\mathrm{e}}$-XXI ${ }^{\mathrm{e}}$ siècles) et les index des noms de personnes et des titres d'œuvres scéniques comme de périodiques et d'autres œuvres (pp. 821-978). La tâche était difficile et parfois le résultat peut sembler manquer de synthèse (malgré la conclusion, pp. 633-640), mais à qui veut trouver information et éclairage sur telle ou telle œuvre, cet ouvrage fournira toute réponse souhaitable de mise en contexte théâtral et en situation générique: c'est à cela qu'on reconnaît un livre de référence. 